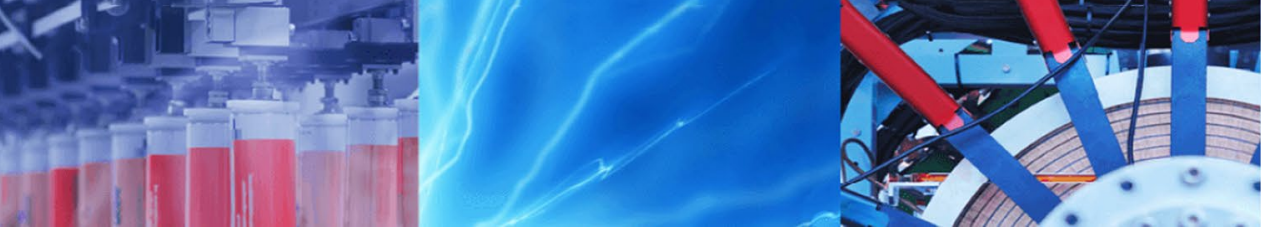

Research Article

\title{
Grains, grids and mineral surfaces: approaches to grain-scale matrix modeling based on X-ray micro-computed tomography data
}

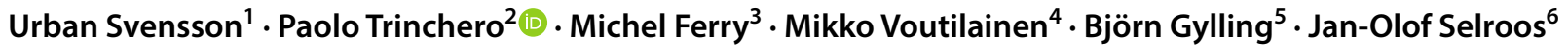

(c) Springer Nature Switzerland AG 2019

\begin{abstract}
$\mathrm{X}$-ray micro-computed tomography $(\mathrm{X}-\mu \mathrm{CT})$ generates 3D mineral distribution maps currently with a resolution of about $10 \mu \mathrm{m}$. For tight crystalline rocks, this implies that the mineral grains are well resolved, while micro-fractures, having apertures of less than $10 \mu \mathrm{m}$, are not resolved. In this study, we propose a method to analyze the properties (size, volume, surface area) of the mineral grains based on $\mathrm{X}-\mu \mathrm{CT}$ data. The numerical approach uses a resolution similar to that of the $\mathrm{X}-\mu \mathrm{CT}$ data and hence shares the same limitations. For example, it is clear that a large fraction of the mineral surface area is due to so-called roughness, with scales below $10 \mu \mathrm{m}$. In the second part of the study, methods to generate the diffusion-available pore space are discussed. The inter-granular space (distance between grains) is often smaller than $10 \mu \mathrm{m}$, and we need to design methods to be able to perform diffusion simulations in the matrix. Three methods, all based on $\mathrm{X}-\mu \mathrm{CT}$, are discussed, and it is demonstrated that models with realistic global properties (mean porosity and effective diffusion coefficient) can be developed based on the suggested techniques.
\end{abstract}

Keywords X-ray micro-computed tomography · Inter-granular space · Grain surface area · Numerical grid

\section{Introduction}

The need for an accurate description and characterization of micro-scale physical and mineralogical properties of subsurface rock formations along with the increasing availability of X-ray micro-computed tomography $(\mathrm{X}-\mu \mathrm{CT})$ machineries have encouraged the use of pore-scale direct numerical modeling of single and multi-phase flow and multicomponent reactive transport [3,11, and references therein].

Most of these works focus on relatively permeable and porous rock samples, typically sandstones $[1,2,16]$ or carbonates $[2,15]$ or synthetically generated sphere packs $[4,12]$, where flow plays a critical role and call for the use of appropriate equations (typically, Navier-Stokes) and numerical schemes.
In parallel to these applications, which are all somehow motivated by oil- and gas-related projects, recently, increasing attention has been directed toward the use of micro-characterization data for numerical simulations for the support of safety analyses of deep geological repositories for nuclear waste. The main difference as compared to the previously mentioned oil- and gas-related works is that the focus here is mostly on the rock matrix of fractured crystalline rocks, which could be unaltered or partly altered due to, e.g., hydrothermal alteration events and which is often characterized by low permeability. A schematic view of the mineral structure and the inter-granular space is shown in Fig. 1. In these types of media, molecular diffusion is the main transport mechanism to be considered and, given the very low amount of available pore

Paolo Trinchero, paolo.trinchero@amphos21.com; Urban Svensson, us@cfe.se; Michel Ferry, mf@mfrdc.com; Mikko Voutilainen, mikko.voutilainen@alumni.helsinki.f; Björn Gylling, bjorn.gylling.konsult@skb.se; Jan-Olof Selroos, jan-olof.selroos@skb.se | ${ }^{1}$ Computer-Aided Fluid Engineering AB, Frankes väg 3, 37165 Lyckeby, Sweden. ${ }^{2}$ AMPHOS 21 Consulting S.L., c/Veneçuela, 103, 2nd Floor, 08019 Barcelona, Spain. ${ }^{3}$ MFRDC, 6 rue de la Perche, 44700 Orvault, France. ${ }^{4}$ Department of Chemistry, University of Helsinki, P.O. Box 55, 00014 Helsinki, Finland. ${ }^{5}$ Gylling GeoSolutions, 3556 Davis Street, Evanston, IL 60203, USA. ${ }^{6}$ Swedish Nuclear Fuel and Waste Management Company, Box 3091, 16903 Solna, Sweden. 


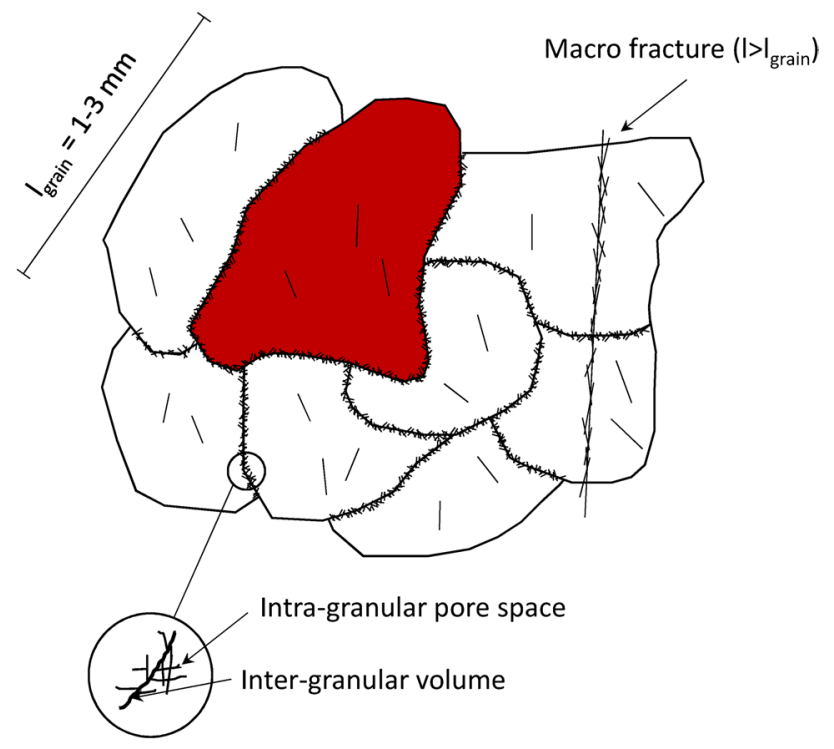

Fig. 1 Sketch showing distribution of grains and pore space in a typical crystalline rock matrix. Red indicates reactive mineral

space of these rock samples, which is typically below the resolution of $\mathrm{X}-\mu \mathrm{CT}$ measurements, the related microscale models have been denoted as grain-scale models. Grain-scale models have been used in combination with different numerical schemes and with different reactive transport mechanisms included.

Voutilainen et al. [27] used X- $\mu \mathrm{CT}$ and ${ }^{14} \mathrm{C}-\mathrm{PMMA}$ measurements of an altered Tonalite sample to map porosity and diffusivity in an underlying continuum model. With the derived heterogeneous distribution of parameters, they simulated diffusion of a non-sorbing radionuclide using a time-domain particle tracking method. The same approach was recently further extended to account for spatially variable retention using a linear sorption model and with $K_{d}$ values related to the underlying distribution of mineral grains [28]. A grain-scale continuum formulation was also used by Trinchero et al. [24] to assess the influence of mineralogical heterogeneity on radionuclide breakthough curves in a single fracture-matrix system using multicomponent reactive transport calculations.

In parallel to the development of continuum-based models, efforts have been placed to map and represent the inter-granular pore space, which is where most of the reactive surface area is exposed to diffusive fluxes. Iraola et al. [7] mapped grain-to-grain discontinuities in a regular lattice, denoted as inter-granular network (IGN), which was used to carry out high-performance computing (HPC) calculations of radionuclide diffusion. The model included an explicit description of mineral surfaces (at the discontinuities of reactive mineral grains), whose sparse distribution was found to lead to anomalous signatures in the resulting diffusive penetration profiles. Svensson et al. [22] showed that the inter-granular space could be represented using a micro-discrete fracture network (micro-DFN), which was subsequently represented in an underlying micro-continuum model. Compared to the work of Iraola et al. [7], this approach offers the advantage of recasting smallscale heterogeneity through an appropriate choice of the parameters of the micro-DFN.

Here, the approach of Svensson et al. [22] is extended and combined with available micro-characterization data of rock samples. More specifically, the proposed method is used to provide direct estimations of grain-related properties from X- $\mu C T$ measurements (e.g., size, volume, surface area, shape factor, etc.). Moreover, different strategies to discretize the diffusion-available pore space are presented, in which $\mathrm{X}-\mu \mathrm{CT}$ data are combined with micro-DFN realizations. The resulting numerical grids are expected to be a valuable tool for, e.g., the study of scale dependence of mineral reaction rates.

\section{Rock samples}

Two types of crystalline rock samples from Olkiluoto, Finland, will be analyzed in this work. The selected veined gneiss (VGN) and pegmatitic granite (PGR) samples represent the typical rock types of Olkiluoto. Their porosity, mineralogy and transport properties have been widely studied previously $[6$, $8,9,13,17,18,29]$. The analyzed samples are collected from the experimental site of the "rock matrix REtention PROperties" (REPRO) project carried out at the underground rock characterization facility of Olkiluoto (ONKALO), at a depth of around $400 \mathrm{~m}$. The project consists of various in situ and laboratory experiments that aim at determining transport properties of the crystalline rock under in situ conditions. Porosities of the samples, obtained from the site, have been determined using water gravimetry, Ar-gas pycnometry [26] and 14C-PMMA autoradiography $[5,14]$. The bedrock of the REPRO site consists of VGN, and PGR and they represent the typical rock types of Olkiluoto [23]. The values of porosity obtained for samples from the REPRO site vary between $(0.3-1.3) \%$ for VGN and $(0.30-0.75) \%$ for PGR $[6,9]$.

Furthermore, effective diffusion coefficients were determined using through-diffusion experiments of HTO and $\mathrm{Cl}-36$ in the laboratory. The obtained values were in the range $(1.7-3.9) \times 10^{-13} \mathrm{~m}^{2} / \mathrm{s}$ for VGN and around $5 \times 10^{-13} \mathrm{~m}^{2} / \mathrm{s}$ for PGR [29]. Other experimental results, obtained with gas phase measurements [9], showed that slightly lower diffusion coefficients are obtained in VGN samples $\left((0.5-1.0) \times 10^{-13} \mathrm{~m}^{2} / \mathrm{s}\right)$ and similar values as above for PGR samples.

Previously Voutilainen et al. [30] have resolved the $3 \mathrm{D}$ mineral structure of the samples with $\mathrm{X}-\mu \mathrm{CT}$ and 
determined the porosity distribution with C-14-PMMA autoradiography. Furthermore, they have constructed 3D grain maps of the samples by first segmentating different main mineral phases from each other by their X-ray attenuation coefficient and then grains from mineral phases by running a watershed algorithm on 3D mineral phase images. The main minerals of the samples are quartz, plagioclase, K-feldspar and mica minerals. Unfortunately, the X-ray attenuation of quartz and plagioclase overlap, and thus they cannot be segmented from each other directly. However, the grains belonging to a mineral phase that included quartz and plagioclase were artificially divided according to their known abundances [17]. The constructed 3D grain maps (see Fig. 2) form the base of the present work and are being further processed in order to create more realistic grain-scale models. The 3D grain maps were 8-bit gray scale images. The gray scale values of each grain were artificially selected so that different minerals had their own gray scale range and no grain has the same gray scale value as any of its neighboring grains (see Table 1).

\section{Methodology and results}

\subsection{Grain and mineral surface analysis}

As explained above, each grain type has its own gray scale value and a mineral phase is built up of a certain range of gray scale values (see Table 1). Here a numerical method will be used to analyze grain properties by considering one gray scale value at the time and then add up a range of gray scale values to get the properties of a mineral phase. The starting point of the procedure is the 3D grain maps obtained by Voutilainen et al. [30]. The analysis is carried out using the numerical groundwater flow and solute
Table 1 Grain map: summary of mineral type, mineral volume fraction and gray value indexes for each of the two considered samples

\begin{tabular}{lllc}
\hline Rock & Mineral & $\begin{array}{l}\text { Abun- } \\
\text { dance } \\
(\%)\end{array}$ & Gray value index \\
\hline Veined gneiss (VGN) & Quartz & 28 & $40-52$ \\
& Plagioclase & 14 & $100-112$ \\
& K-feldspar & 16 & $120-132$ \\
& Mica minerals & 42 & $60-72$ \\
Pegmatitic granite & Quartz & 46 & $20-32$ \\
(PGR) & Plagioclase & 21 & $100-112$ \\
& K-feldspar & 31 & $41-53$ \\
& Mica minerals & 2 & $60-72$ \\
\hline
\end{tabular}

transport code DarcyTools [20, 21]. The following stepwise approach is adopted:

1. Each considered rock sample is "covered" with a uniform grid, with a resolution of $27.16 \mu \mathrm{m}$ (i.e., twice as much as the resolution of the $\mathrm{X}-\mu \mathrm{CT}$ data).

2. Each cell in the grid is marked with a gray scale value, as given by the grain map. One of the gray scale values of the analyzed mineral phase is selected for analysis. All cells not having the selected value are removed from the grid.

3. The remaining grid will form patches that are not connected. Each such patch represents a grain, and the number of patches is thus equal to the number of grains of the considered type.

4. Each patch is analyzed individually by computing its total volume $\left(\mathrm{m}^{3}\right)$ and total surface area $\left(\mathrm{m}^{2}\right)$.

5. Results for each mineral type are computed by adding up the contribution from their corresponding grain indexes (see Table 1). For example, if K-feldspar in PGR is to be analyzed, we need to consider gray scale values $41-53$. Steps $2-4$ are then repeated thirteen times
Fig. 2 Three-dimensional visualization of the two considered rock samples (left: pegmatitic granite, PGR; right: veined gneiss, VGN) after mineral segmentation. The size of each sample is $1 \mathrm{~cm}^{3}$. The mineral phases shown are : quartz (blue), plagioclase (green), K-feldspar (yellow) and mica (red)
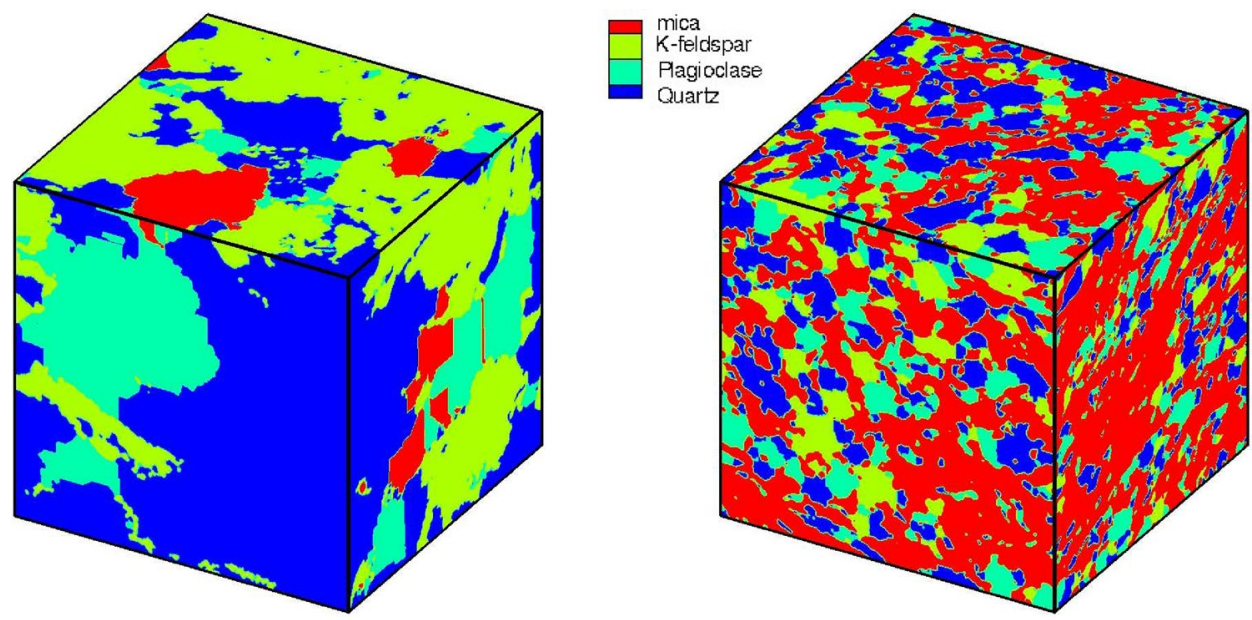

SN Applied Sciences A SPRINGER NATURE journa 
before adding up the contributions from the range of grains constituting K-feldspar.

Besides volume and surface area, a shape factor (-) is also computed as the ratio between the surface area of a given grain and the surface area of a sphere with the same volume as the considered grain. As a sphere encloses the maximum volume for a given surface area (minimum surface-to-volume ratio), the shape factor can be seen as a measure of the surface-to-volume ratio or irregularity of mineral grains. Note that here the grain size is not defined as typically in crystallography. Here the fissures, fractures and grain boundaries are considered to divide crystallographic grains into multiple grains (for further details see Voutilainen et al. [30]).

Some numerical aspects of the calculation of grain surface area and shape factor are given in "Appendix".

The results of the analysis are summarized in Table 2 . In VGN, the four identified mineral phases distribute in grains with a similar size $(0.4-0.7 \mathrm{~mm})$. Most of the available surface area belongs to mica minerals: $\approx 49 \%$. This relative amount is slightly higher than the mica mineral volume fraction ( $\approx 42 \%$, see Table 1$)$, due to the smaller size and higher surface-to-volume ratio of mica grains compared to, e.g., K-feldspar grains ( $11 \%$ of surface area and $16 \%$ of volume fraction).

The size of mineral grains in PGR spans a larger range: from $0.5 \mathrm{~mm}$ for K-feldspar to $1.1 \mathrm{~mm}$ for plagioclase. Around $58 \%$ of the available surface area belongs to these two mineral phases. K-feldspar grains are significantly smaller, which explains the fact that they account for $44 \%$ of the available mineral surface area with only $31 \%$ of the volume fraction.

Histograms and bar graphs for size and other metrics that characterize each mineral grain of a given mineral phase have been computed and are shown in Fig. 3 for mica minerals in VGN and Fig. 4 for plagioclase in PGR. Mica is the most abundant mineral phase in VGN and is constituted by more than 18,000 individual mineral grains, whose size spans a range from a few tens of micro-meters to a few millimeters, for the few larger grains. Despite accounting for $21 \%$ of the volume fraction in PGR, plagioclase is constituted by a few hundred grains only. In fact, most of this volume fraction is associated with two single individual grains of diameter larger than $4 \mathrm{~mm}$. The distribution of shape factors is significantly more scattered for mica minerals in VGN than plagioclase in PGR. Yet, a general trend can be observed for both phases, with the shape factor increasing from a value slightly higher than 1 for the smallest grains to a plateau value, for grains with larger radii. This plateau value is slightly higher for mica minerals $(\approx 2.8$ for mica minerals in $V G N$ and $\approx 2.5$ for plagioclase in $P G R$ ), which indicates that the mineral grains of this phase have a slightly higher surface-to-volume ratio. A close-up view of some plagioclase grains in VGN is shown in Fig. 5.

\subsection{Grids generation}

The objective here is to define and test methodologies for the generation of numerical grids that map the diffusionavailable porosity of a rock sample and that can be of use for transport calculations.

The basic idea is illustrated in Fig. 6. The inter-granular space is typically below the resolution of $X$-ray data (i.e., below $10 \mu \mathrm{m}$ ). Thus, a numerical grid, with refinement equal to the resolution of X-ray data, is used to "cover" the whole rock sample and only the grid cells located at boundaries between two different grains are retained. Based on this idea, three different approaches for mapping the inter-granular space and for defining local values of pore diffusivity and porosity are defined. A description of these approaches, and the related numerical grids, is as follows.

- Grid 1 The numerical grid is generated using the approach shown in Fig. 7a; i.e., two grid cells are used to describe the boundary between two adjacent mineral grains. Constant values of local pore diffusivity and porosity are assigned.

- Grid 2 A micro-discrete fracture network (micro-DFN, [22]) is generated in a volume slightly bigger than the considered sample. Only fractures having their center
Table 2 Grain map: summary of number of grains, specific surface area (SSA), relative amount of surface area (SA) and mean diameter of the grains for each of the two considered samples

\begin{tabular}{llclcc}
\hline Rock & Mineral & Number of grains & $\begin{array}{l}\text { SSA } \\
\left(\mathrm{m}^{2} / \mathrm{m}^{3}\right) \times 10^{3}\end{array}$ & $\begin{array}{l}\text { SA (\%) } \\
\text { Veined gneiss (VGN) }\end{array}$ & $\begin{array}{l}\text { Mean diame- } \\
\text { ter }(\mathrm{m}) \times 10^{-4}\end{array}$ \\
& Quartz & 7196 & 4.9 & 25 & 5.2 \\
& Plagioclase & 7081 & 2.8 & 15 & 4.0 \\
& K-feldspar & 1555 & 2.1 & 11 & 7.0 \\
& Mica minerals & 18,563 & 9.4 & 49 & 4.2 \\
Pegmatitic granite & Quartz & 6430 & 3.5 & 40 & 6.3 \\
(PGR) & Plagioclase & 528 & 1.2 & 14 & 11.2 \\
& K-feldspar & 8209 & 3.9 & 44 & 5.3 \\
& Mica minerals & 70 & 0.2 & 2 & 10.0 \\
\hline
\end{tabular}



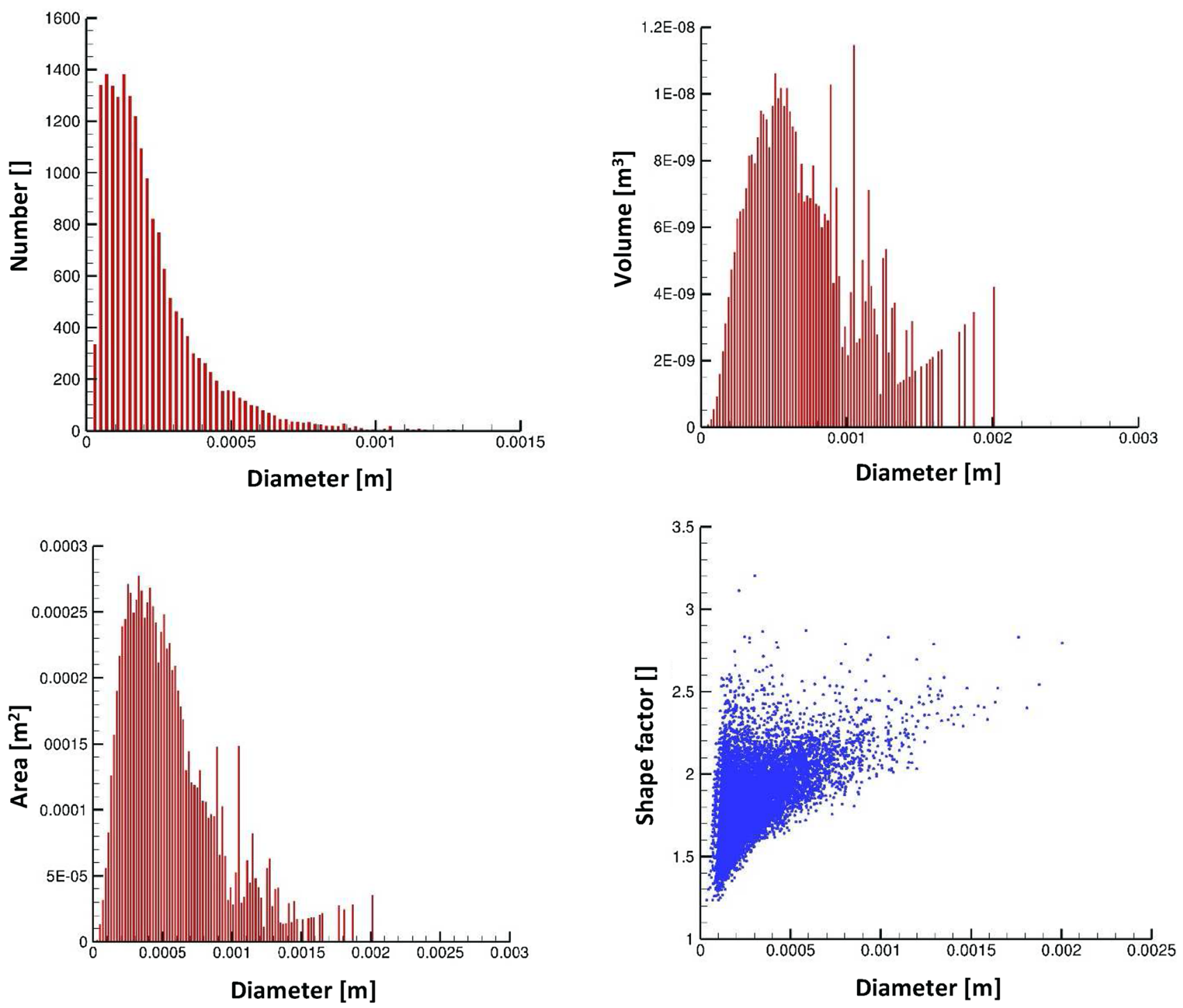

Fig. 3 Mica minerals in VGN. For the given mineral, the histogram of size distribution (bin size $20 \mu \mathrm{m}$; the bin size defines the number of grains in the interval $(d, d+20 \mu \mathrm{m}))$ is calculated (top left). The bar graphs for volume (top right) and area (bottom left) are also calculated using the same bin size. The volume of each grain

inside the volume occupied by Grid 1 are retained. Those grid cells of Grid 1 not intersected by any fracture are deactivated while DFN-derived diffusivity and porosity values are assigned to the other cells (see Svensson [19] for details on how DFN-derived values are computed). A sketch of this approach is shown in Fig. 7b. The topology of the resulting numerical grid is similar to that of Grid 1, the main difference being that Grid 2 is less connected.

- Grid 3. This numerical grid is generated in a way analogous to Grid 2, but here previously deactivated cells located at the far-end of fractures are re-activated. This grid aims at including the effect of intra-granular porosity.

is computed assuming a spherical shape in order to be able to use "diameter" as the variable on the horizontal axes. The surface area of the grain divided by the area of the sphere gives the shape factor (bottom right)

It is worthwhile recalling that in DarcyTools, fracture orientation follows a Fisher distribution (here a random orientation is used) and spatial centers are statistically independent and follow a Poisson process. The number of fractures in the length interval $I$ to $I+d l$ is simulated using the following power law equation:

$n=\frac{I}{a}\left[\left(\frac{I+d l}{I_{\text {ref }}}\right)^{a}-\left(\frac{I}{I_{\text {ref }}}\right)^{a}\right]$

where $n$ is the number of fractures per unit volume, $I\left(\mathrm{~m}^{-3}\right)$ is the intensity, $a(-)$ is the power law exponent and $I_{\text {ref }}$ 

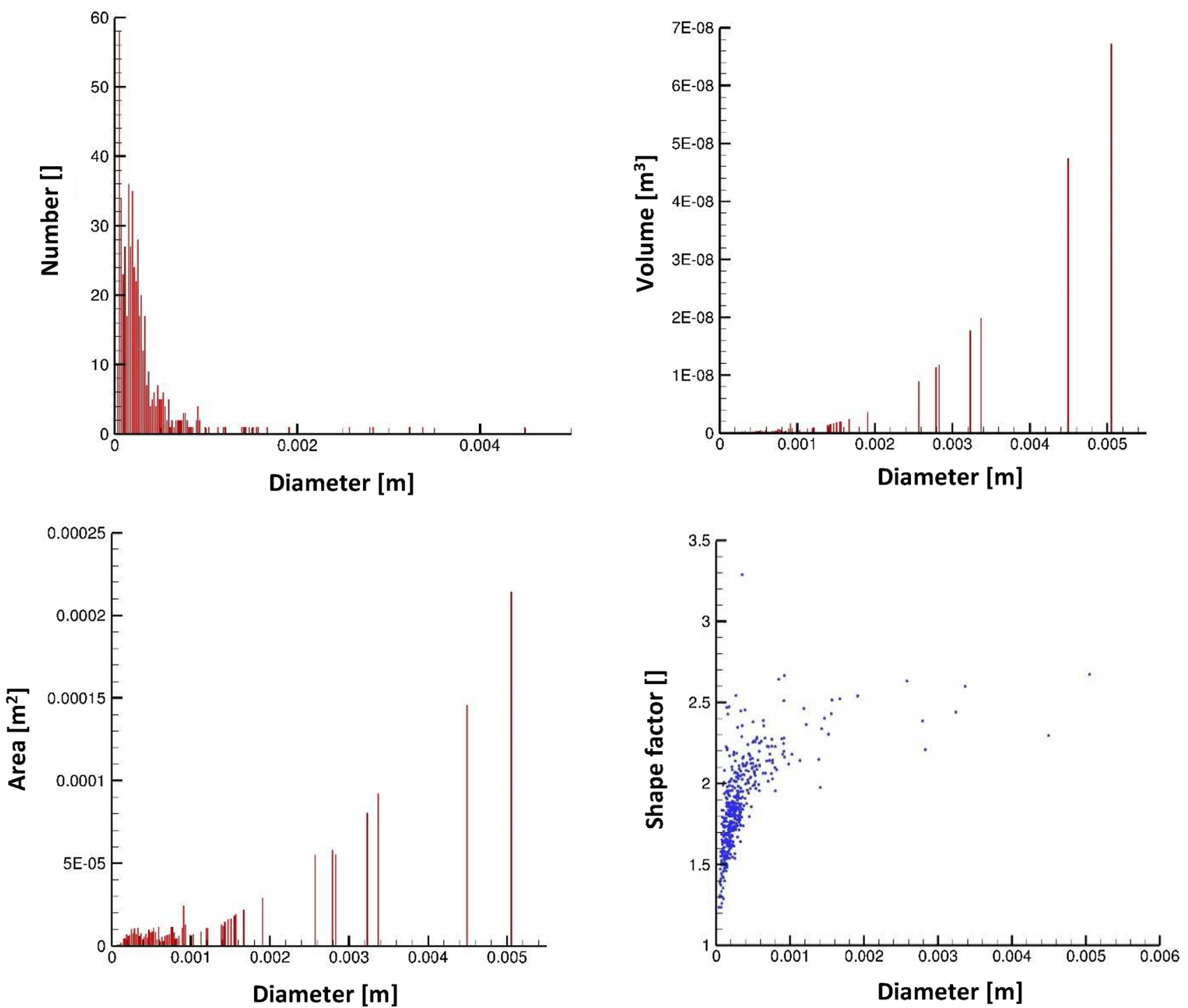

Fig. 4 Plagioclase in PGR. For the given mineral, the histogram of size distribution (bin size $20 \mu \mathrm{m}$; the bin size defines the number of grains in the interval $(d, d+20 \mu \mathrm{m}))$ is calculated (top left). The bar graphs for volume (top right) and surface area (bottom left) are also calcu-

$(\mathrm{m})$ is the reference length, which is here set to $1 \mathrm{~m} . I_{\text {ref }}$ is strictly not needed as a variable as it could be included in the intensity. However, it is motivated by dimensional and numerical arguments.

The three approaches are here tested using the two data-sets described in Sect. 2. The target metrics that are used to fine-tune the grid parameterization are global properties typically obtained using laboratory experiments, namely porosity and effective diffusivity, which are also summarized in Sect. 2.

Local properties are set, and manually calibrated, to match the range of diffusion-related global properties discussed previously. The calibration is done by adjusting the aperture and the diffusion coefficient. Global porosity is

lated using the same bin size. The volume of each grain is computed assuming a spherical shape in order to be able to use "diameter" as the variable on the horizontal axes. The area of the grain divided by the area of the sphere gives the shape factor (bottom right)

obtained as the arithmetic mean of local porosity, whereas global diffusivity is computed from numerical steady state through diffusion experiments. As an example, Fig. 8 shows the spatial distribution of steady-state concentration for one of the considered models (namely, Grid 2 for VGN).

The numerical experiment is set up as follows. A cube is given properties from the micro-DFN. Two opposing sides of the cube are given fixed value (Dirichlet) boundary conditions; other boundaries are of zero flux type. A steady-state diffusion calculation is carried out and the flux through the cube is noted. From the flux and the concentration gradient, the global diffusivity can be calculated.

For Grid 1, local porosity and pore diffusivity are set to constant values of $2 \%$ and $2 \times 10^{-12} \mathrm{~m}^{2} / \mathrm{s}$, for VGN and 

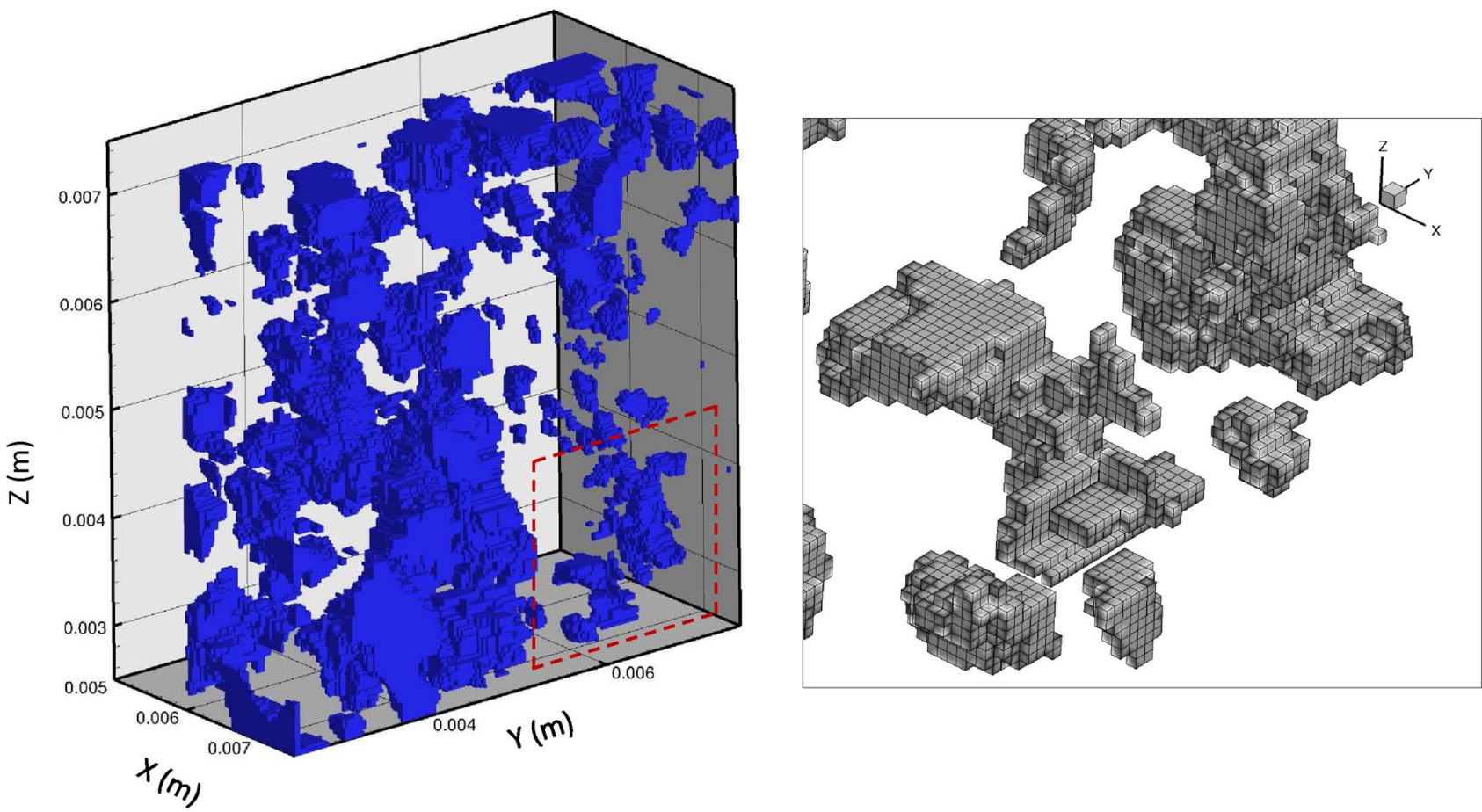

Fig. 5 Grain map analysis. Illustration of resolved plagioclase grains in VGN. The figure to the right is an enlargement of the bottom right part of the figure to the left, which is indicated by a red dashed frame. The cell size used for the analysis is $27.16 \mu \mathrm{m}$

Fig. 6 Transport grids.

Concepts and Methods. The inter-granular region (left) is expected to have a spacing of 1-10 $\mu \mathrm{m}$. X-ray data does not resolve this (center). The shaded cells (right) constitute the reference case computational grid
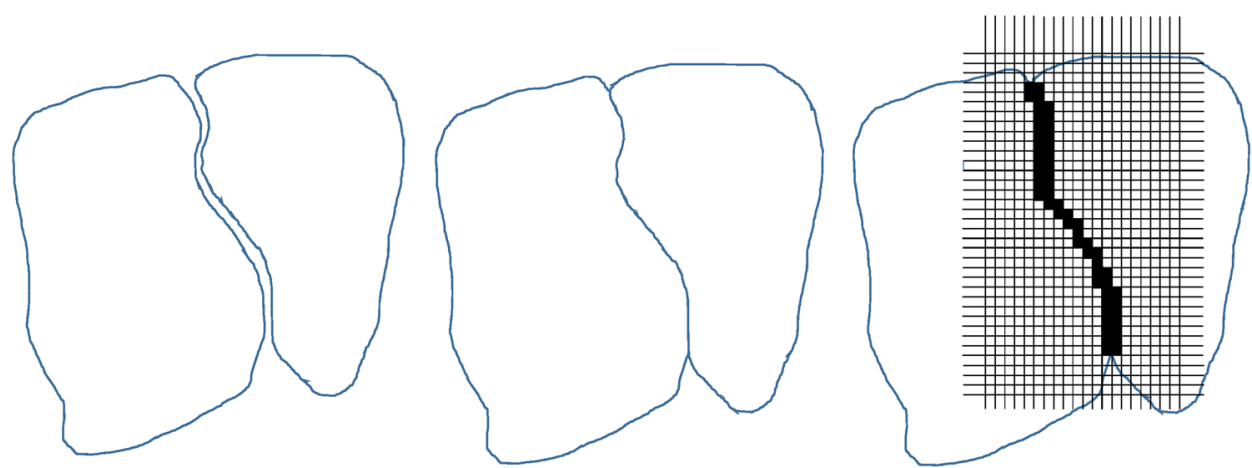

Ten to twenty-six million cells are required to map the diffusion-available pore space in VGN (less cells are required in the less connected Grid 2 while more cells are needed in Grid 3, which includes intra-granular pore space). Significantly less cells are used for the PGR sample (4.6 millions for Grid 2 and 12.5 millions for Grid 3) due to the fact that this sample is characterized by a significantly lower amount of grains (see Table 2).

Figures $9,10,11,12,13$ and 14 show the different grids used to map the diffusion-available pore space of the VGN and PGR samples. For Grid 1 (Figs. 9, 10), grid cells are colored according to the grain value index of the neighboring grain. For Grid 2 and Grid 3 (Figs. 11, 12, $13,14)$ local porosity values are shown. The simple visual inspection of these numerical grids points out that Grid 1 

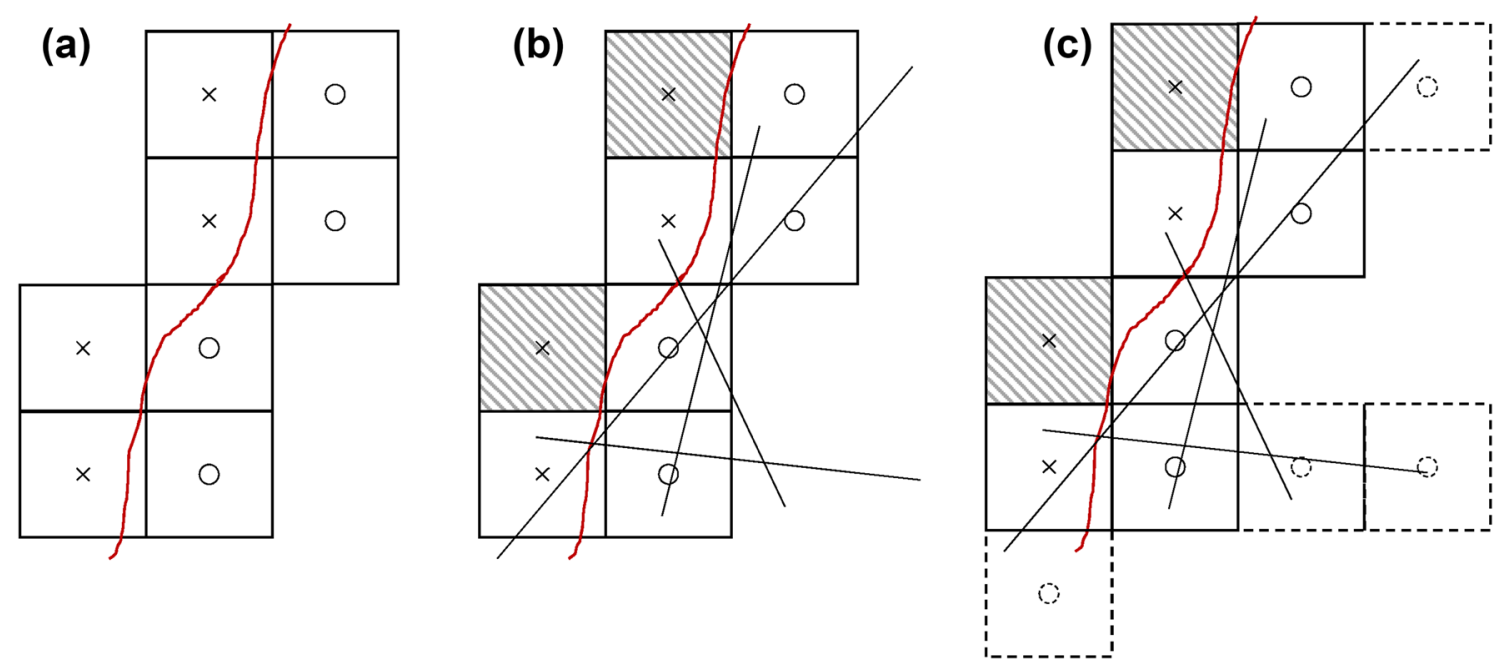

Fig. 7 Three approaches to the generation of grids for transport simulations. In this sketch the red line indicates the limit between two adjacent grains and cells belonging to two different grains are marked with a circle and a cross. a Grid 1: boundary cells are retained (i.e., all the cells shown in the plot) and the rest are deac- tivated. b Grid 2: a discrete fracture network is generated and fractures intersecting active grid cells are retained. Cells not intersected by fractures are also deactivated (gray shaded cells). c Grid 3: additional cells (marked with dashed lines) are added at the far-end of fractures to mimic intra-granular porosity
Fig. 8 Grid 2 of VGN: steadystate distribution of concentration of a non-sorbing tracer. Concentration is normalized by the concentration at the upstream boundary. $y$-section is taken at $y=5 \mathrm{~mm}$

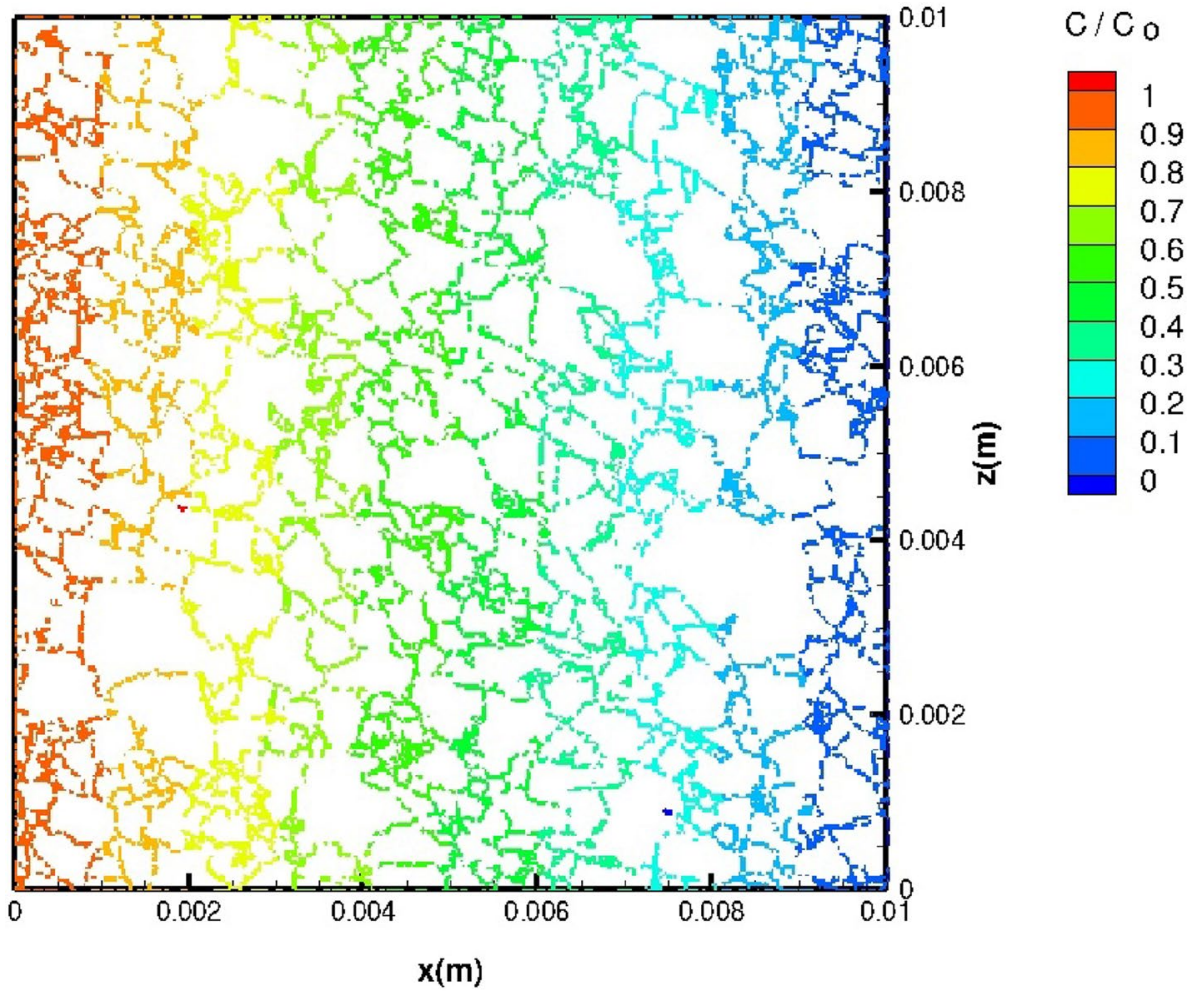

Fig. 11) seems to indicate the opposite. In Grid 3 a significantly larger number of cells are activated. This grid in fact accounts for the influence of intra-granular pore space. It is also possible to visually notice the difference between the VGN and the PGR samples. The latter is characterized by larger grains, which results in a smaller number of is indeed over-connected, as a full layer of cells will surround each grain. This over-connection is broken in Grid 2, which accounts for small-scale heterogeneity through an underlying micro-DFN (see, for instance, Fig. 15). Yet, it is worthwhile emphasizing that Grid 2 is still connected in 3D even though a visual inspection of a 2D cross section (e.g.,

\section{SN Applied Sciences}


Table 3 Micro-DFN parameters: fracture diffusivity, fracture aperture and intensity. Common for all: length interval $(50 \rightarrow 100 \mu \mathrm{m})$, power law coefficient $(-2.6)$ and random orientation. Note that $D_{f}$ is the local diffusivity value of each considered fracture

\begin{tabular}{llllll}
\hline Property & \multicolumn{2}{l}{ VGN } & & \multicolumn{2}{l}{ PGR } \\
\cline { 2 - 3 } \cline { 6 - 6 } & Grid 2 & Grid 3 & & Grid 2 & Grid 3 \\
\hline$D_{\mathrm{f}}\left(\mathrm{m}^{2} / \mathrm{s}\right) \times 10^{-10}$ & 2.0 & 1.0 & & 9.0 & 3.0 \\
Aperture $(\mu \mathrm{m})$ & 1.2 & 0.3 & & 2.8 & 0.5 \\
Intensity $\left(1 / \mathrm{m}^{3}\right)$ & 100 & 400 & & 100 & 400 \\
\hline
\end{tabular}

Table 4 Global properties computed for the two different samples and with the different grids: effective diffusion coefficient $\left(D_{\mathrm{e}}\right)$, porosity $(\Phi)$, number of cells and grid volume fraction (i.e., percentage of the total volume occupied by active cells, $V_{f}$ )

\begin{tabular}{llllll}
\hline Rock & Grid & $\begin{array}{l}D_{\mathrm{e}} \\
\left(\mathrm{m}^{2} / \mathrm{s}\right) \times 10^{-13}\end{array}$ & $\Phi(\%)$ & $\begin{array}{l}\text { Number of } \\
\text { cells (million) }\end{array}$ & $V_{f}(\%)$ \\
\hline $\begin{array}{l}\text { Veined gneiss } \\
\text { (VGN) }\end{array}$ & 1 & 2.9 & 0.58 & 14.4 & 29 \\
& 2 & 3.2 & 0.58 & 10.1 & 20 \\
& 3 & 4.0 & 0.75 & 26.0 & 52 \\
Pegmatitic & 1 & 4.7 & 0.66 & 6.6 & 13 \\
granite (PGR) & 2 & 4.5 & 0.60 & 4.6 & 9 \\
& 3 & 6.3 & 0.57 & 12.5 & 25 \\
\hline
\end{tabular}

cells used to map the diffusion-available pore space (see Table 4). This explains also the higher value of local porosity used in Grid 1 of PGR compared to the analogous values used in Grid 1 of VGN.

An illustration of a generated micro-DFN is given by Fig. 15. In the present context, we have chosen to only use the global porosity and the effective diffusivity as our target metrics. The micro-DFN approach can, however, be tuned to model other parameters (like tortuosity and porosity distributions) as shown in Svensson et al. [22]. Nevertheless, it should be emphasized that the micro-DFN is a model of the inter-granular space. For example, the length interval has been chosen to $50-100 \mu \mathrm{m}$, even though smaller fractures/ patches may contribute significantly to the total porosity. With the parameters in Table 3 this fracture length interval will result in 1-5 million fractures. For computational reasons we cannot use smaller fractures as too many fractures would be generated. Another simplification is that all fractures are rectangles with constant aperture and diffusivity. The tuning of the model can for these reasons not be based on direct observations of the inter-granular space; a more pragmatic view is needed. Here we have chosen a certain fracture length interval and a certain power law coefficient. We then tune the diffusivity, aperture and intensity. The task is simplified by noting that the apertures and intensities control the global porosity, while the diffusivities and apertures control the effective diffusivity. The DFN parameters in Table 3 can thus not be directly compared to measured data, but we still require that they are within certain limits. The diffusivities should, for example, be smaller than the molecular diffusivity in unconstrained solution and the apertures significantly smaller than the side length of the fracture.

\section{Discussion and conclusions}

We have presented an approach for the direct analysis of grain properties (volume, surface area, size distribution, shape factor, etc.) from X-ray computed microtomography

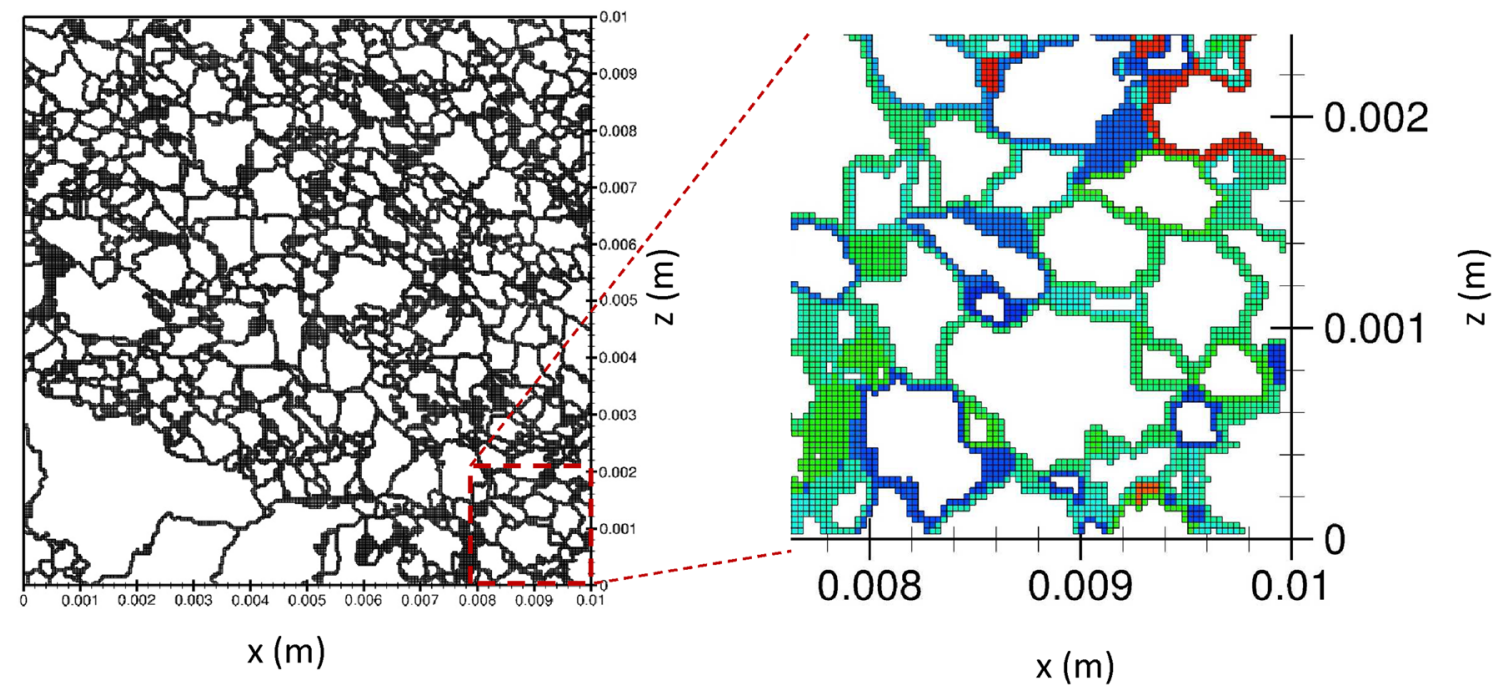

Fig. 9 (Left) Grid 1 of VGN and (right) close-view showing grid cells colored according to the grain value index of the neighboring grain. $y$-section is taken at $y=5 \mathrm{~mm}$ 


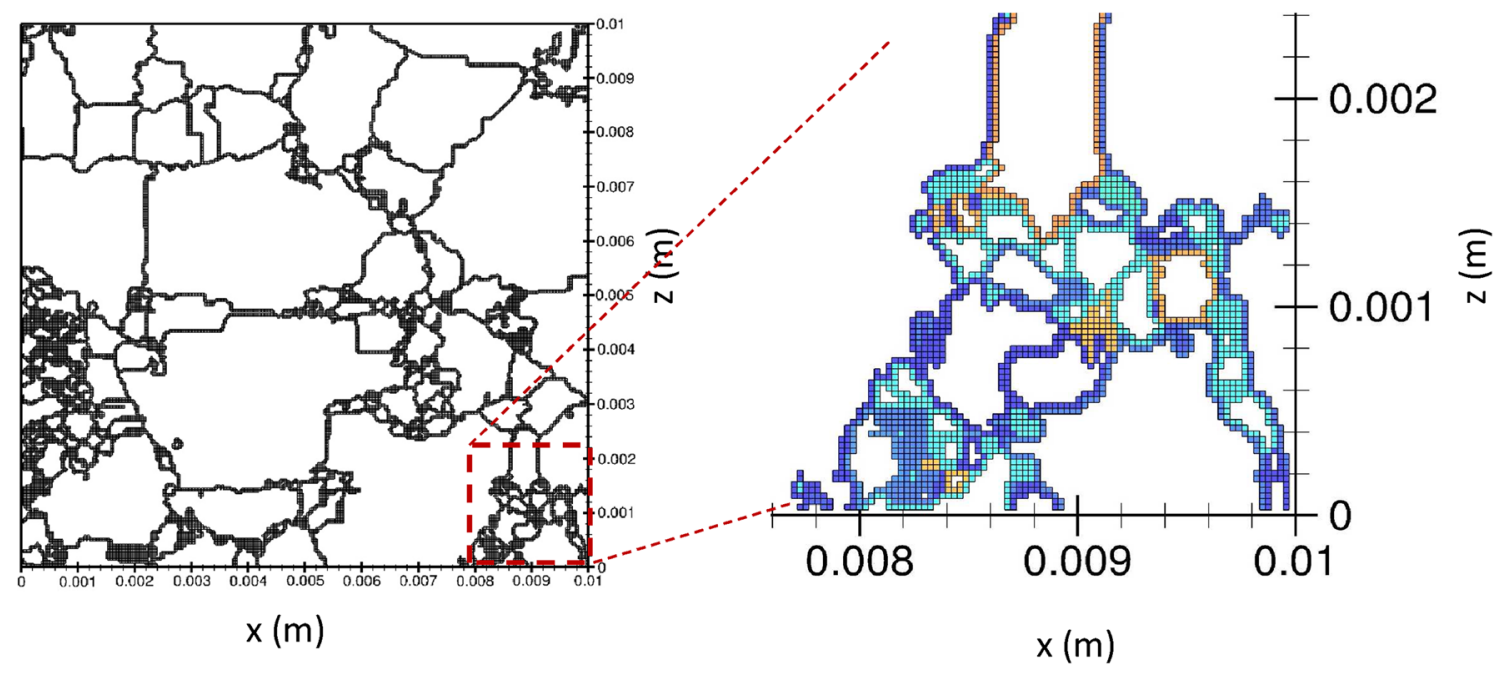

Fig. 10 (Left) Grid 1 of PGR and (right) close-view showing grid cells colored according to the grain value index of the neighboring grain. $y$-section is taken at $y=5 \mathrm{~mm}$

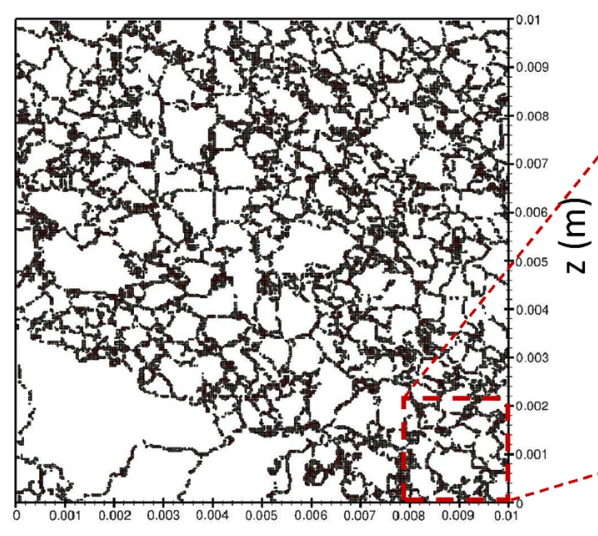

$x(m)$
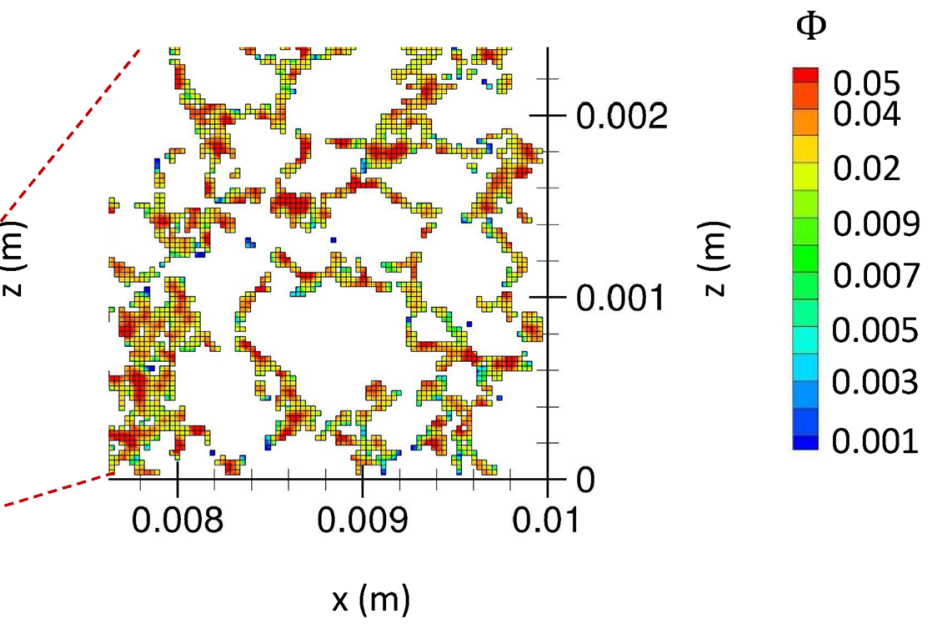

Fig. 11 (Left) Grid 2 of VGN and (right) close-view showing grid cells colored according to their porosity value. $y$-section is taken at $y=5 \mathrm{~mm}$
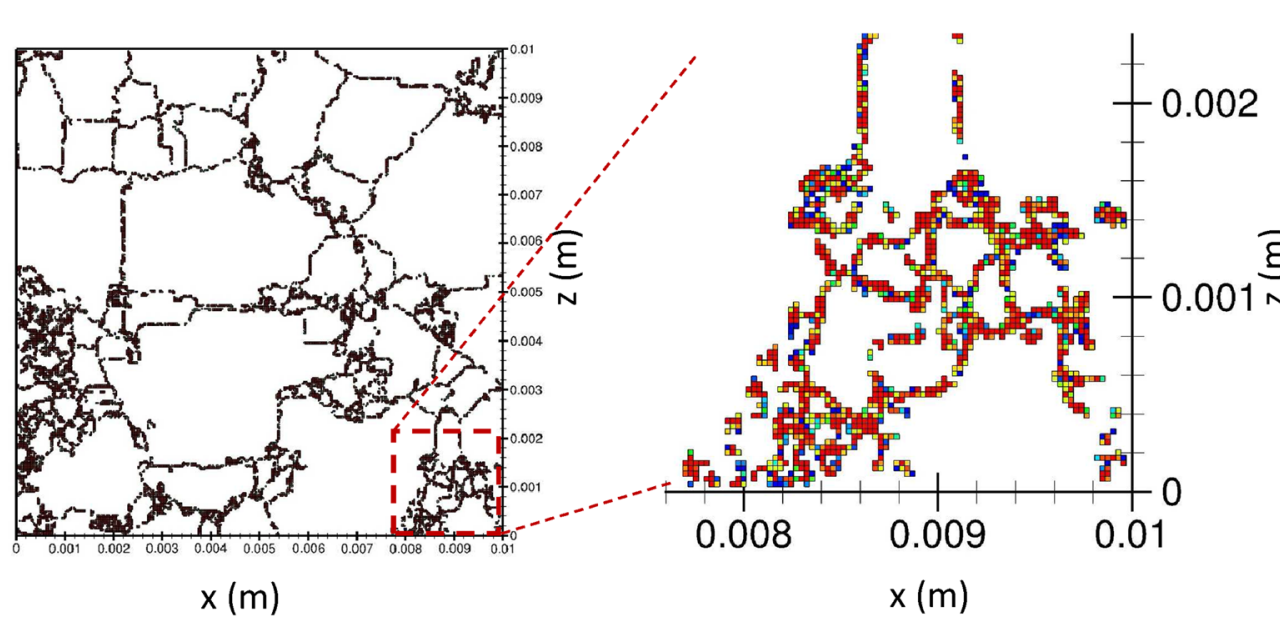

$\Phi$

0.05
0.04
0.02
0.009
0.007
0.005
0.003
0.001

Fig. 12 (Left) Grid 2 of PGR and (right) close-view showing grid cells colored according to their porosity value. $y$-section is taken at $y=5 \mathrm{~mm}$ 


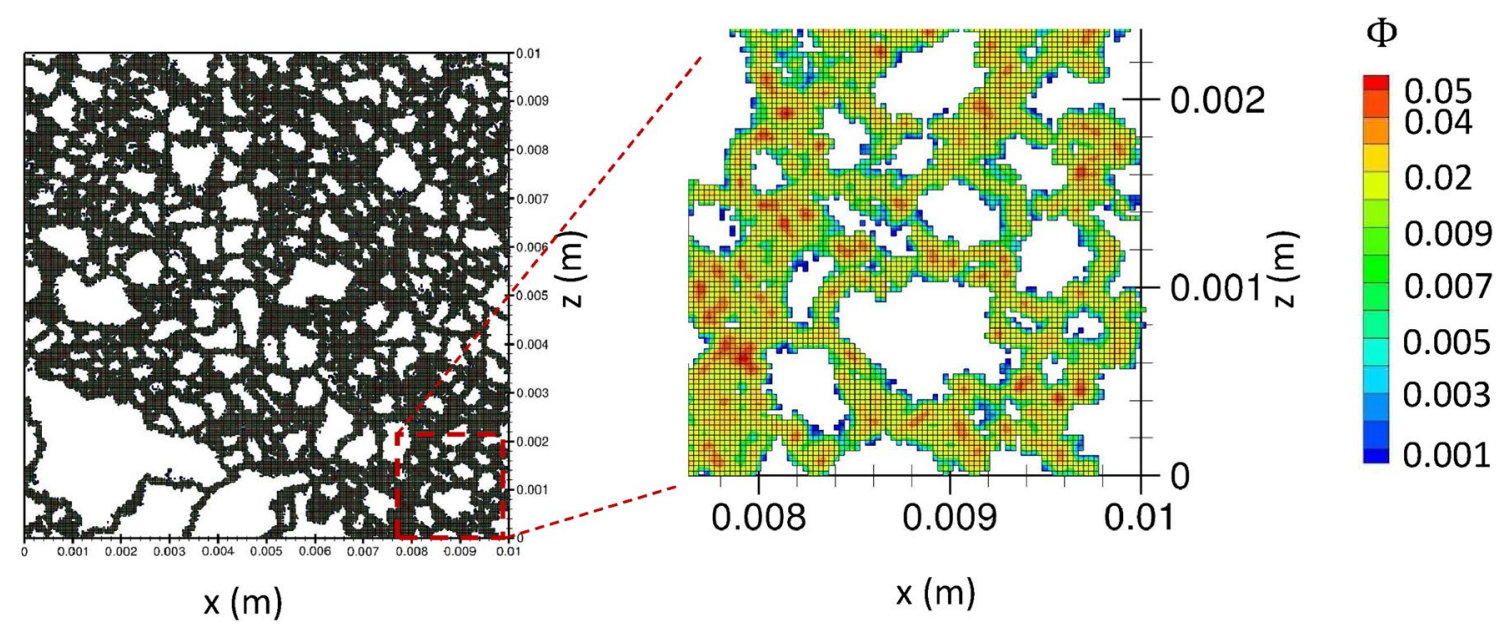

Fig. 13 (Left) Grid 3 of VGN and (right) close-view showing grid cells colored according to their porosity value. $y$-section is taken at $y=5 \mathrm{~mm}$

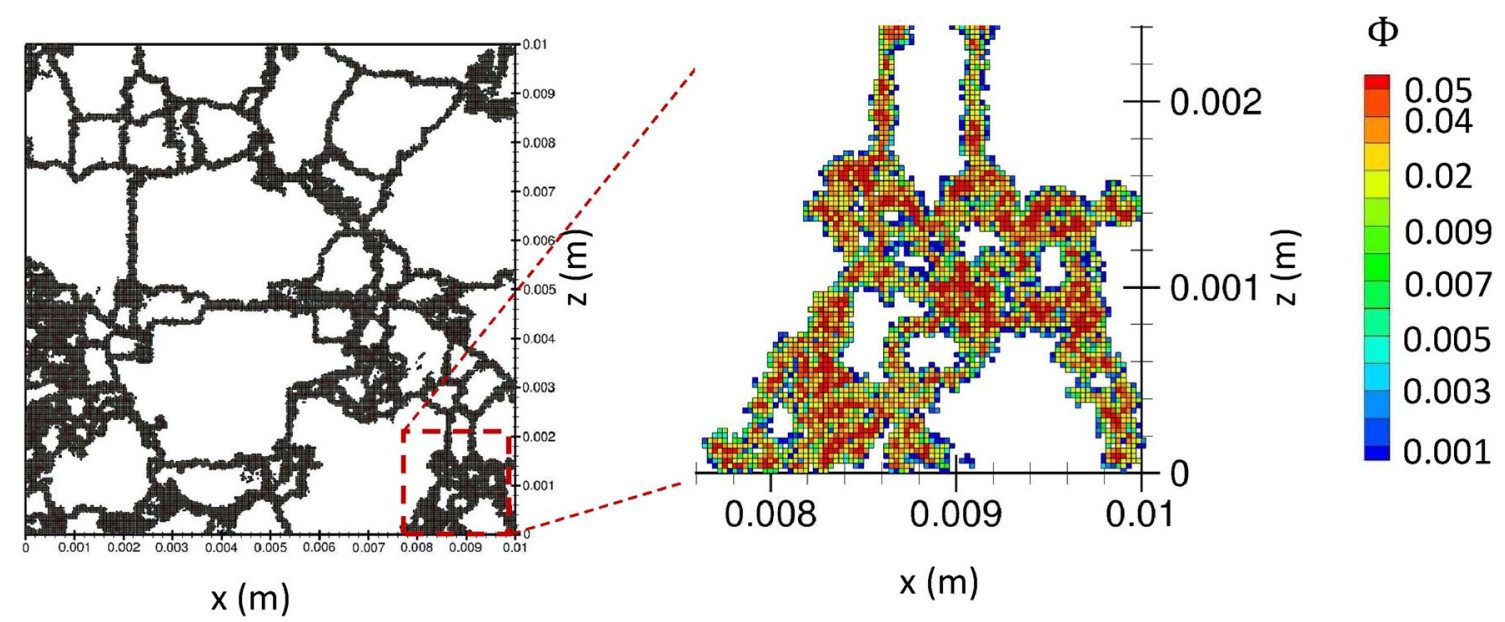

Fig. 14 (Left) Grid 3 of PGR and (right) close-view showing grid cells colored according to their porosity value. $y$-section is taken at $y=5 \mathrm{~mm}$

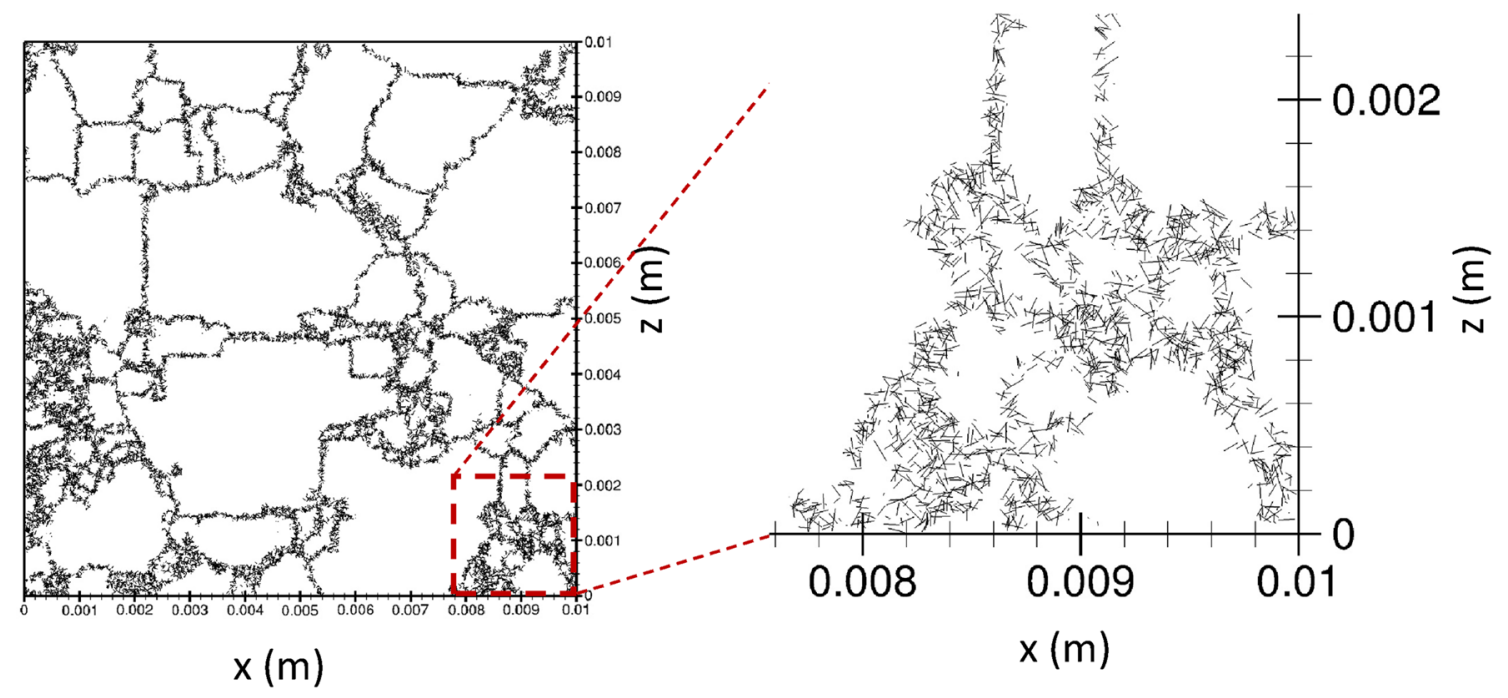

Fig. 15 Fracture traces of the discrete fracture network used in Grid 3 of PGR 
data. The proposed methodology can be used to assess individually each grain of each mineral phase and to estimate statistical properties of important parameters, such as the amount of surface area available for geochemical reactions. Bulk averaged values of specific surface area and grain size can also be derived for use in larger-scale reactive transport models.

The estimates of mineral surface area are representative of the resolution of the X- $\mu \mathrm{CT}$ analyses $(\approx 20 \mu \mathrm{m}$ for the two rock samples considered in this work). This means that the amount of mineral surface area related to smaller-scale roughness is not resolved by the approach. This also explains the discrepancy between the estimated value of mineral surface area and analogous estimates obtained using the Brunauer-Emmett-Teller (BET) method. The latter is expected to be 1-2 orders of magnitude higher than the values calculated from the X-ray data [10]. Muuri et al. [13] report BET value results for the typical rock types of Olkiluoto. For veined gneiss values of $1.4798 \pm 0.0155 \mathrm{~m}^{2} / \mathrm{g}$ were determined, while for pegmatitic granite lower values, $0.3416 \pm 0.0034 \mathrm{~m}^{2} / \mathrm{g}$, were found. From Table 2, the summed-up areas for the two rock types can be used to calculate the corresponding areas in $\mathrm{m}^{2} / \mathrm{g}$. Using a density of $2700 \mathrm{~kg} / \mathrm{m}^{3}$, we find a value of $7.1 \times 10^{-3} \mathrm{~m}^{2} / \mathrm{g}$ for veined gneiss and $3.6 \times 10^{-3} \mathrm{~m}^{2} / \mathrm{g}$ for pegmatitic granite. Measured BET values are hence about two orders of magnitude larger, which agrees with the estimate by Lai et al. [10], discussed above.

We have also presented an approach to analyze and discretize the diffusion-available pore space of a considered rock sample. The approach is similar to that presented by Iraola et al. [7] in that the primary focus is placed on mapping the inter-granular space (i.e., the space between adjacent mineral grains). However, a combined use of micro-DFN and X- $\mu \mathrm{CT}$ data is here proposed to recast smaller-scale heterogeneity (Grid 2) and to account for the influence of intra-granular space (Grid 3). By calibrating the local values of porosity and diffusivity (Grid 1), or fine-tuning the statistics and parameters of the underlying micro-DFN (Grid 2 and 3), the different

Table 5 Mineral specific surfaces as represented in the computational grids $\left(\left(\mathrm{m}^{2} / \mathrm{m}^{3}\right) \times 10^{3}\right)$

\begin{tabular}{lllll}
\hline Rock & Mineral & Grid 1 & Grid 2 & Grid 3 \\
\hline Veined gneiss (VGN) & Quartz & 3.3 & 3.4 & 3.2 \\
& Plagioclase & 1.8 & 1.8 & 1.6 \\
& K-feldspar & 1.5 & 1.5 & 1.6 \\
& Mica minerals & 6.0 & 6.1 & 5.4 \\
Pegmatitic granite (PGR) & Quartz & 2.3 & 2.4 & 2.6 \\
& Plagioclase & 1.0 & 1.0 & 1.2 \\
& K-feldspar & 2.6 & 2.6 & 2.6 \\
& Mica minerals & 0.1 & 0.1 & 0.2 \\
\hline
\end{tabular}

SN Applied Sciences

A SPRINGER NATURE journal models have been able to provide bulk values of porosity and effective diffusivity consistent with laboratory measurements carried out in similar rock samples. Interestingly, despite being based on different approaches, the estimates of bulk mineral specific surface area obtained from the numerical grids are consistent with the values inferred from direct mapping of the $X-\mu C T$ data (see Tables 2, 5). It turns out that the proposed numerical grid can be seen as a potential tool for, e.g., studying and upscaling the rate of mineral reaction (e.g., [25]) or to analyze the influence of mineralogical heterogeneity on radionuclide sorption and diffusion (e.g., [7]).

Acknowledgements US, MF, BG and PT thank the Swedish Nuclear Fuel and Waste Management Company (SKB) for the financial support.

\section{Compliance with ethical standards}

Conflict of interest On behalf of all authors, the corresponding author states that there is no conflict of interest.

\section{Appendix: A note on the calculation of grain surface areas and grain shape factors}

\section{Introduction}

A visualization of how grains are represented on the computational grid is given by Fig. 5 . The grains can be analyzed individually and the volume, $V$, and surface area, $A$, are then obtained. A shape factor, $\mathrm{SF}$, is defined as the ratio between the surface area of a given grain and the surface area of a sphere with the same volume as the considered grain:

$\mathrm{SF}=\frac{A}{4 \pi}\left(\frac{3 V}{4 \pi}\right)^{-\frac{2}{3}}$

From Fig. 5 it is clear that the grain surface area is described in a stair-case fashion, i.e., the normal vector of the faces is always in a coordinate direction. This is obviously an approximation of a real grain surface area and in this Appendix, we will investigate the implications of this approximation.

\section{The sphere}

Let us assume that a grain is a perfect sphere. The shape factor is then 1.0 by definition. How well the grain is represented on a Cartesian grid depends on the ratio between the cell size, $h$, and the diameter, $d$, of the grain. In Fig. 16 two examples are shown. As we have fixed a cell size and there is a range of grain sizes, a grain can be represented by one cell or by a large number (for 

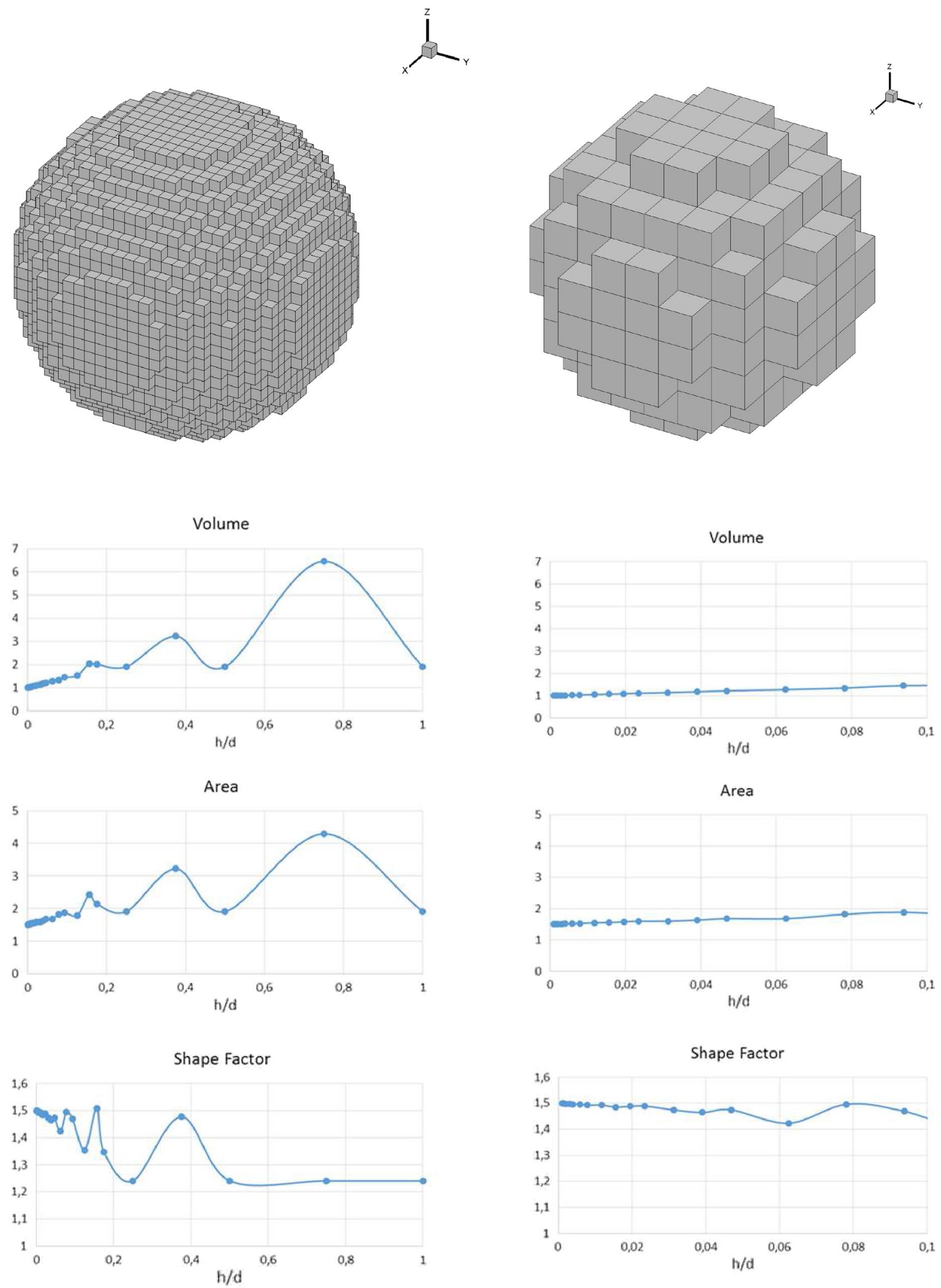

Fig. 16 The sphere. The sphere as represented in a grid for $h / d=0.039$ (top left) and $h / d=0.156$ (top right). Normalized volume, area and shape factor, as a function of $h / d$. The $x-y$ plots on the right are enlargements of the corresponding plots on the left 

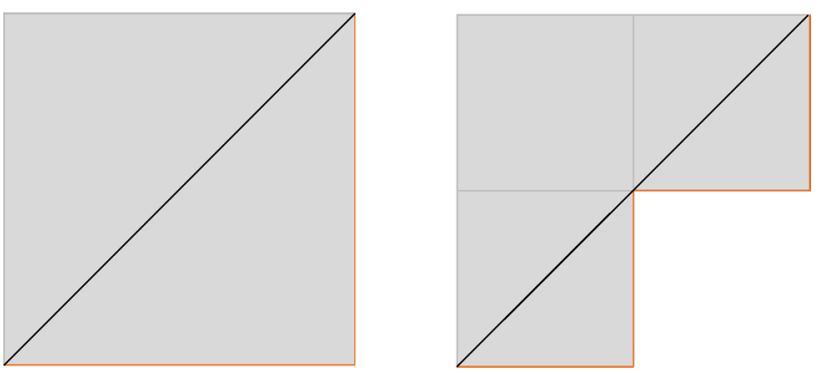

Fig. 17 The estimated length of the diagonal is not improved by grid refinement

a large grain) of cells. In Fig. 16 the calculated volume, surface area and shape factor are shown as a function of $h / d$. The volume and area are normalized with the correct values for a sphere. We find that the normalized volume goes to 1.0 as $h / d$ decreases, while the normalized area goes to a value of 1.6. This results in a SF that deviates from 1.0. From Fig. 16 the SF is seen to be around 1.5 for small $h / d$.

The fact that the volume converges to the right value while the area is calculated erroneously is explained by Fig. 17. A two-dimensional square with side length $L$ is shown and we want to calculate the length of the diagonal. Using the same approach as in our surface area calculations, we approximate the length to $2 L$. Next, we refine the grid and obtain four cells. One of the new cells can be removed (and the volume calculation is improved) but the length estimate is still $2 L$. It is realized that grid refinement will not solve the problem and this explains the error in the grain surface area calculations.

\section{The cube}

Next, we assume that the grain is a cube of side length $d$. The shape factor for a cube is 1.2407 . So, if a grain is represented by $1,8,27 \ldots$ cells the shape factor is 1.2407 , provided the cells form a perfect cube. In Fig. 3 , it is possible to see dots for a shape factor of 1.2407 and different diameters. If two cells represent a grain the shape factor is 1.39 and if three cells are contributing the number is
Fig. 18 The cube $45^{\circ}-20^{\circ}-45^{\circ}$. The cube as represented in a grid for $h / d=0.0469$ (top left) and $h / d=0.1875$ (top right). Normalized volume, area and shape factor, as a function of $h / d$. The $x-y$ plots on the right are enlargements of the corresponding plots on the left

1.48. For four cells, and more, different formations are possible.

However, since any surface that is not aligned with a coordinate direction causes an error in the surface area calculation, the cubic grain orientation has been investigated. For this reason, successive rotations of the cube from $0^{\circ}$ to $45^{\circ}$ in steps of $5^{\circ}$ was performed around the three coordinate directions. The worst case, in term of shape factor, was sought and the largest shape factor found was 2.06, this for a rotation of $45^{\circ}-20^{\circ}-45^{\circ}$. The rotation was made around the $z$-axis, then the $y$-axis and finally the $x$-axis with one corner fixed. Figure 18 illustrates the results for this worst orientation. The area is normalized with the area of the cube and the error factor is found to converge toward 1.67. The shape factor can hence be regarded as having two components; a "true" shape factor of 1.2407 and a surface representation error.

\section{Conclusions}

This brief investigation of the numerical estimates of grain surface area and grain shape factor has revealed two main issues:

- Grain surface area. A stair-case representation of the grain surface introduces an error that does not decrease with increased resolution, i.e., smaller cell sizes. For two idealized shapes, the sphere and the cube, factors of 1.50 and 1.67 were found.

- Grain shape factor. The calculation of the shape factor, as defined in the present work, is affected by the error in the grain surface area calculation. The calculated values can hence be regarded as the product of a "true" shape factor and the surface error factor. 

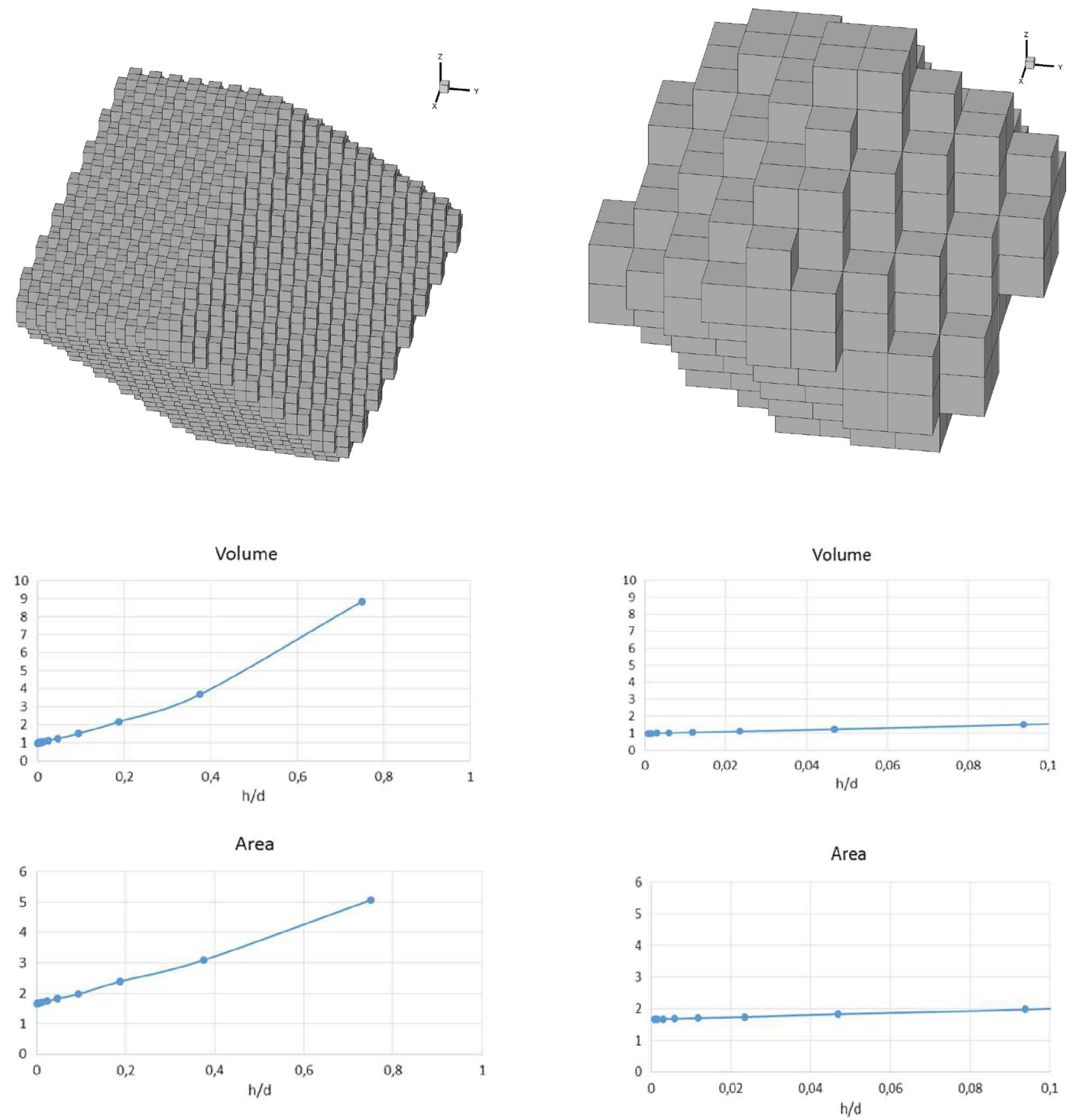

Shape Factor

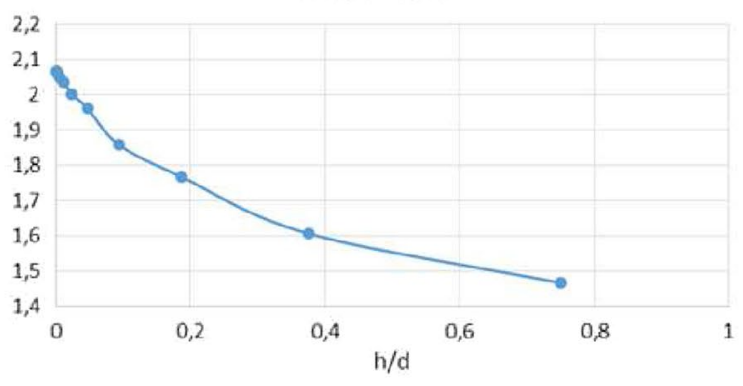

Shape Factor

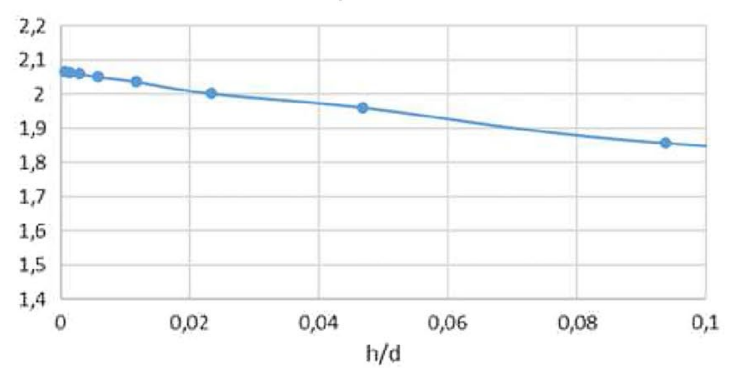




\section{References}

1. Bijeljic B, Mostaghimi P, Blunt MJ (2011) Signature of non-Fickian solute transport in complex heterogeneous porous media. Phys Rev Lett 107(20):204502

2. Bijeljic B, Raeini A, Mostaghimi P, Blunt MJ (2013) Predictions of non-Fickian solute transport in different classes of porous media using direct simulation on pore-scale images. Phys Rev E 87(1):013011

3. Blunt MJ, Bijeljic B, Dong $H$, Gharbi O, Iglauer S, Mostaghimi $P$, Paluszny A, Pentland C (2013) Pore-scale imaging and modelling. Adv Water Resour 51:197-216

4. Cardenas MB (2009) Direct simulation of pore level Fickian dispersion scale for transport through dense cubic packed spheres with vortices. Geochem Geophys Geosyst 10(12):QC12041

5. Hellmuth K, Siitari-Kauppi M, Lindberg A (1993) Study of porosity and migration pathways in crystalline rock by impregnation with 14C-polymethylmethacrylate. J Contam Hydrol 13(1):403-418

6. Ikonen J, Sammaljärvi J, Siitari-Kauppi M, Voutilainen M, Lindberg A, Kuva J, Timonen J (2014) Investigation of rock matrix retention properties. Supporting laboratory studies I: mineralogy, porosity and pore structure. Technical report WR 2014-68, Posiva Oy, Eurajoki, Finland

7. Iraola A, Trinchero P, Voutilainen M, Gylling B, Selroos J-O, Molinero J, Svensson U, Bosbach D, Deissmann G (2017) Microtomography-based inter-granular network for the simulation of radionuclide diffusion and sorption in a granitic rock. J Contam Hydrol 207:8-16. https://doi.org/10.1016/j.jconhyd.2017.10.003

8. Kärki A, Paulamäki S (2006) Petrology of Olkiluoto. Technical report POSIVA report 2006-02, Posiva Oy, Olkiluoto, Finland

9. Kuva J, Voutilainen $M$, Kekäläinen P, Siitari-Kauppi M, Timonen J, Koskinen L (2015) Gas phase measurements of porosity, diffusion coefficient, and permeability in rock samples from Olkiluoto bedrock, finland. Transp Porous Media 107(1):187-204

10. Lai P, Moulton K, Krevor S (2015) Pore-scale heterogeneity in the mineral distribution and reactive surface area of porous rocks. Chem Geol 411:260-273

11. Molins S (2015) Reactive interfaces in direct numerical simulation of pore scale processes. Rev Mineral Geochem 80:461-481

12. Molins S, Trebotich D, Steefel Cl, Shen C (2012) An investigation of the effect of pore scale flow on average geochemical reaction rates using direct numerical simulation. Water Resour Res 48(3):W03527

13. Muuri E, Sorokina T, García D, Grivé M, Bruno J, Koskinen L, Martin A, Siitari-Kauppi M (2018) The in-diffusion of ${ }^{133} \mathrm{Ba}$ in granitic rock cubes from the Olkiluoto and Grimsel in-situ test sites. Appl Geochem 92:188-195. https://doi.org/10.1016/j. apgeochem.2018.03.011

14. Oila E, Sardini P, Siitari-Kauppi M, Hellmuth K-H (2005) The 14C-polymethylmethacrylate (PMMA) impregnation method and image analysis as a tool for porosity characterization of rock-forming minerals. Geol Soc Lond Spec Publ 240(1):335-342

15. Okabe $\mathrm{H}$ (2004) Pore-scale modelling of carbonates. PhD thesis, University of London

16. Salles J, Thovert J, Adler P (1993) Deposition in porous media and clogging. Chem Eng Sci 48(16):2839-2858

17. Sammaljärvi J, Lindberg A, Voutilainen M, Kuva J, Ikonen J, Johanson B, Siitari-Kauppi M, Pitkänen P, Koskinen L (2017) Multi-scale study of the mineral porosity of veined gneiss and pegmatitic granite from Olkiluoto, Western Finland. J Radioanal Nucl Chem 314(3):1557-1575. https://doi.org/10.1007/ s10967-017-5530-5

18. Smellie J, Pitkänen P, Koskinen $L$, Aaltonen I, Eichinger F, Waber N, Sahlstedt E, Siitari-Kauppi M, Karhu J, Löfman J, Poteri A (2014) Evolution of the Olkiluoto site: palaeohydrogeochemical considerations. Technical report POSIVA working report 2014-27, Posiva Oy, Olkiluoto, Finland

19. Svensson U (2001) A continuum representation of fracture networks. Part I: method and basic test cases. J Hydrol 250(1):170-186

20. Svensson U, Ferry M (2014) DarcyTools: a computer code for hydrogeological analysis of nuclear waste repositories in fractured rock. J Appl Math Phys 2(06):365

21. Svensson U, Kuylenstierna H-O, Ferry M (2010) DarcyTools version 3.4: user's guide. Technical report R-10-72, Svensk Kärnbränslehantering $A B(S K B)$, Stockholm, Sweden

22. Svensson U, Löfgren M, Trinchero P, Selroos J-O (2018) Modelling the diffusion-available pore space of an unaltered granitic rock matrix using a micro-DFN approach. J Hydrol 559:182-191

23. Toropainen V (2012) Core drilling of REPRO drillholes in ONKALO at Olkiluoto 2010-2011. Technical report WR 201226, Posiva Oy, Eurajoki, Finland

24. Trinchero P, Molinero J, Deissmann G, Svensson U, Gylling B, Ebrahimi H, Hammond G, Bosbach D, Puigdomenech I (2017) Implications of grain-scale mineralogical heterogeneity for radionuclide transport in fractured media. Transp Porous Media 1:73-90. https://doi.org/10.1007/s11242-016-0765-0

25. Trinchero P, Sidborn M, Puigdomenech I, Svensson U, Ebrahimi H, Molinero J, Gylling B, Bosbach D, Deissmann G (2018) Transport of oxygen into granitic rocks: role of physical and mineralogical heterogeneity. J Contam Hydrol 220:108-118

26. Voutilainen $M$, Siitari-Kauppi $M$, Sardini $P$, Lindberg $A$, Timonen $J$ (2012) Pore space characterization of an altered tonalite by X-ray computed microtomography and the 14C-labeled-polymethylmethacrylate method. J Geophys Res 117:B01201

27. Voutilainen $M$, Sardini $P$, Siitari-Kauppi $M$, Kekäläinen $P$, Aho V, Myllys M, Timonen J (2013) Diffusion of tracer in altered tonalite: experiments and simulations with heterogeneous distribution of porosity. Transp Porous Media 96(2):319-336

28. Voutilainen $M$, Kekäläinen $P$, Siitari-Kauppi $M$, Sardini $P$, Muuri E, Timonen J, Martin A (2017) Modeling transport of cesium in Grimsel granodiorite with micrometer scale heterogeneities and dynamic update of $K_{d}$. Water Resour Res 53(11):92459265. https://doi.org/10.1002/2017WR020695

29. Voutilainen M, Ikonen J, Sammaljärvi J, Siitari-Kauppi M, Lindberg A, Kuva J, Timonen J, Löfgren M (2018) Investigation of rock matrix retention poperties-supporting laboratories studies ii: diffusion coefficient and permeability. Technical report WR 2017-39, Posiva Oy, Eurajoki, Finland

30. Voutilainen $M$, Miettinen A, Sardini P, Parkkonen J, Sammaljärvi J, Gylling B, Selroos J-O, Yli-Kaila M, Koskinen L, Siitari-Kauppi M (2019) Characterization of spatial porosity and mineral distribution of crystalline rock using X-ray micro computed tomography, C-14-PMMA autoradiography and scanning electron microscopy. Appl Geochem 101:50-61. https:// doi.org/10.1016/j.apgeochem.2018.12.024

Publisher's Note Springer Nature remains neutral with regard to jurisdictional claims in published maps and institutional affiliations. 